\title{
THERAPEUTICS \\ Review: decision aids increase patients' knowledge and realistic expectations and reduce decisional conflict
}

O'Connor AM, Stacey D, Entwistle V, et al. Decision aids for people facing health treatment or screening decisions. Cochrane Database Syst Rev 2003;(2):CD001431 (latest version 24 Feb 2003).

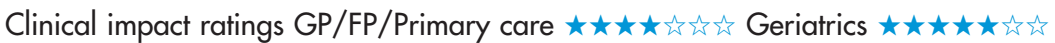

In people making treatment or screening decisions, what are the measurable effects of patient decision aids (interventions designed to help people make choices relevant to their own health status)?

METHODS

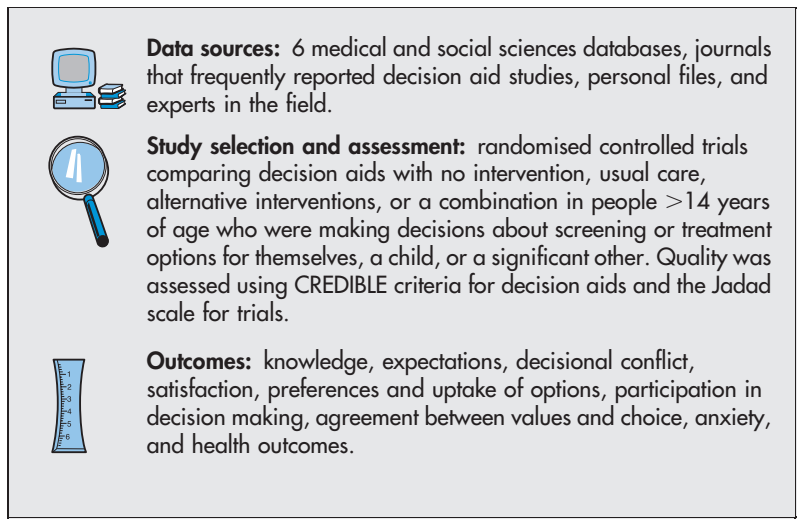

\section{MAIN RESULTS}

34 trials evaluating 30 different decision aids for 16 screening or treatment options met the selection criteria. Decision aids performed better than usual care for the outcomes of knowledge, realistic expectations, preferences and uptake of options, decisional conflict, participation in decision making, and patient indecision (table). Detailed decision aids performed better than simple decision aids for the outcomes of knowledge, realistic expectations (table), and the match between values and choice. 5 of 9 trials showed improvements in satisfaction with the process and decision. Minimal or no differences between groups were seen for anxiety or general health outcomes

For correspondence: $\operatorname{Dr}$ A O'Connor, University of Ottawa, Ottawa, Ontario, Canada. ohdec@ohri.ca

Sources of funding: Canadian Institutes of Health Research; Nuffield Trust of University of Oxford UK; Ontario Ministry of Health Career Scientist; Leverhulme Trust Research Fellowship; Canadian Research Chair Program.

\section{CONCLUSION}

Decision aids enhance knowledge and realistic expectations, and reduce decisional conflict.

\section{Commentary}

ike medical decision making itself, the study of decision aids is complex. Are such aids effective? How should we define their "effectiveness?"

-O'Connor et al have made an impressive effort to summarise the current state of knowledge. By its unprecedented comprehensiveness and rigour, this review makes a novel contribution to the literature.

This broad perspective does, however, result in heterogeneity. Patients and their surrogates, as well as healthy people considering screening, all contributed data to this review. Those studied were considering issues as varied as infant circumcision and cancer surgery. The included studies used a variety of decision aids, ranging from simple pamphlets to interactive computer soffware. Outcomes assessed varied from knowledge to decisional conflict and quality of life. Many of the potential outcomes were measured in different ways: For example, at least 5 scales were used to assess satisfaction with participation in decision making, the decision making process, and the decision itself.

Because of the variation across studies, it is difficult to determine the clinical significance of some effects reported. The statistically significant reduction (weighted mean difference) in total decisional conflict of 5.8\% may or may not be meaningful, depending on the clinical context.

At present, decision aids remain primarily within the research setting. Clinicians considering the use of a specific aid in a given clinical context should seek out the randomised trials specific to their situation to better gauge effectiveness. Frequently, changes in questionnaire scores that correspond to about 0.5 standard deviations are clinically important; however, one must know the instrument well to interpret percentage changes.' Researchers should use the suggestions of this review to focus and standardise future efforts in this field.

Jolie Ringash, MD Princess Margaret Hospital and University of Toronto Toronto, Ontario, Canada

1 Norman GR, Sloan JA, Wyrwich KW. Med Care 2003;41:582-92.

Decision aids (DA) v usual care (UC) and detailed (DDA) v simple decision aids (SDA) for helping patients make treatment and screening decisions*

\begin{tabular}{|c|c|c|c|c|c|}
\hline Outcomes & Number of trials & Comparisons & Weighted mean differe & e out of $100195^{\circ}$ & \\
\hline Knowledge & $\begin{array}{l}9 \\
9\end{array}$ & $\begin{array}{l}\text { DA } v \text { UC } \\
\text { DDA } v \text { SDA }\end{array}$ & $\begin{array}{l}19(13 \text { to } 24) \\
4.4(2.5 \text { to } 6.2)\end{array}$ & & \\
\hline Decisional conflict & $\begin{array}{l}6 \\
4\end{array}$ & $\begin{array}{l}\text { DA } v \text { UC } \\
\text { DDA } v \text { SDA }\end{array}$ & $\begin{array}{l}-5.8(-8.6 \text { to }-2.9) \\
-1.0(-4.5 \text { to } 2.5)\end{array}$ & & \\
\hline & & & Weighted event rates & $\mathrm{RBI}(\mathrm{Cl})$ & NNT (CI) \\
\hline Realistic expectations & $\begin{array}{l}4 \\
4\end{array}$ & $\begin{array}{l}\text { DA } v \text { UC } \\
\text { DDA } v \text { SDA }\end{array}$ & $\begin{array}{l}60 \% \text { > } 42 \% \\
69 \% \text { > } 47 \%\end{array}$ & $\begin{array}{l}44 \% \text { (11 to } 88) \\
45 \% \text { (26 to } 67)\end{array}$ & $\begin{array}{l}6(4 \text { to } 17) \\
5(4 \text { to } 8)\end{array}$ \\
\hline & & & & RRR (CI) & \\
\hline $\begin{array}{l}\text { Preferences and uptake (major surgery) } \\
\text { Remaining undecided } \\
\text { Passive role }\end{array}$ & $\begin{array}{l}5 \\
2 \\
3 \\
7\end{array}$ & $\begin{array}{l}\text { DA } v \text { UC } \\
\text { DDA } v \text { SDA } \\
\text { DA } v \text { UC } \\
\text { DA } v \text { UC }\end{array}$ & $\begin{array}{l}27 \% \text { v } 32 \% \\
24 \% \vee 30 \% \\
3 \% \vee 19 \% \\
15 \% \text { v } 21 \%\end{array}$ & $\begin{array}{l}24 \%(9 \text { to } 37) \\
22 \%(-7 \text { to } 43) \\
57 \%(30 \text { to } 73) \\
32 \%(11 \text { to } 47)\end{array}$ & $\begin{array}{l}\text { Not significant } \\
\text { Not significant } \\
7(4 \text { to } 100) \\
\text { Not significant }\end{array}$ \\
\hline
\end{tabular}

*Abbreviations defined in glossary; RBI, RRR, NNT, and Cl calculated from data in article using a random effects model. All significant differences favour decision aids over usual care or detailed over simple decision aids.

†Scale for knowedge ranged from 0 (no correct responses) to 100 (all accurate responses) and scale for conflict ranged from 0 (no decisional conflict) to 100 (extreme decisional conflict). 